\title{
Cardiovascular disease risk and comparison of different strategies for blood pressure management in rural India
}

\author{
Devarsetty Praveen ${ }^{1,2^{*}}$ D, David Peiris ${ }^{3}$, Stephen MacMahon ${ }^{4}$, Kishor Mogulluru ${ }^{5}$, Arvind Raghu ${ }^{6}$, Anthony Rodgers ${ }^{4}$, \\ Shailaja Chilappagari ${ }^{3}$, Dorairaj Prabhakaran ${ }^{7,8}$, Gari D. Clifford ${ }^{9,10}$, Pallab K. Maulik ${ }^{11}$, Emily Atkins ${ }^{4}$, Rohina Joshi ${ }^{4}$, \\ Stephane Heritier ${ }^{12}$, Stephen $\operatorname{Jan}^{4}$ and Anushka Patel ${ }^{4}$
}

\begin{abstract}
Background: Non-optimal blood pressure (BP) levels are a major cause of disease burden globally. We describe current BP and treatment patterns in rural India and compare different approaches to BP lowering in this setting.

Methods: All individuals aged $\geq 40$ years from 54 villages in a South Indian district were invited and 62,194 individuals (84\%) participated in a cross-sectional study. Individual 10-year absolute cardiovascular disease (CVD) risk was estimated using WHO/ISH charts. Using known effects of treatment, proportions of events that would be averted under different paradigms of BP lowering therapy were estimated.

Results: After imputation of pre-treatment BP levels for participants on existing treatment, $76.9 \%$ (95\% confidence interval, 75.7-78.0\%), 5.3\% (4.9-5.6\%), and 17.8\% (16.9-18.8\%) of individuals had a 10-year CVD risk defined as low $(<20 \%)$, intermediate (20-29\%), and high ( $\geq 30 \%$, established CVD, or BP > 160/100 $\mathrm{mmHg}$ ), respectively. Compared to the 19.6\% (18.4-20.9\%) of adults treated with current practice, a slightly higher or similar proportion would be treated using an intermediate $(23.2 \%(22.0-24.3 \%))$ or high (17.9\% (16.9-18.8\%) risk threshold for instituting BP lowering therapy and this would avert $87.2 \%$ (85.8-88.5\%) and 62.7\% (60.7-64.6\%) more CVD events over ten years, respectively. These strategies were highly cost-effective relative to the current practice.
\end{abstract}

Conclusion: In a rural Indian community, a substantial proportion of the population has elevated CVD risk. The more efficient and cost-effective clinical approach to BP lowering is to base treatment decisions on an estimate of an individual's short-term absolute CVD risk rather than with BP based strategy.

Clinical trial registration: Clinical Trials Registry of India CTRI/2013/06/003753, 14 June 2013.

Keywords: Cardiovascular disease, Absolute risk, India, Treatment, Blood pressure

\section{Background}

Cardiovascular diseases (CVD) are a major cause of premature morbidity and mortality globally, with ischemic heart disease and stroke responsible for $24.4 \%$ of all deaths in $2010[1,2]$. About $80 \%$ of these CVD deaths occur in low-and middle-income countries [3]. CVD rates have decreased in developed nations due to major public health interventions and better preventive treatment, but they are a major contributor to the increasing

\footnotetext{
* Correspondence: dpraveen@georgeinstitute.org.in

${ }^{1}$ The George Institute for Global Health, Hyderabad, India

${ }^{2}$ University of New South Wales, Sydney, Australia

Full list of author information is available at the end of the article
}

burden of non-communicable diseases in developing countries [4-6]. In India, CVD already cause about $27 \%$ of deaths, indicating a rapid pace of epidemiological transition [7].

Modifiable CVD risk factors (including tobacco use, physical activity levels, blood pressure [BP], blood cholesterol, and diabetes) are common and are amenable to effective public health and clinical interventions [8-11]. Traditionally, clinical management of CVD risk factors has been based on directing treatment at abnormal levels of individual risk factors (i.e. treating "hypertension" or elevated cholesterol levels), however guidelines worldwide are increasingly incorporating

(c) The Author(s). 2018 Open Access This article is distributed under the terms of the Creative Commons Attribution 4.0 International License (http://creativecommons.org/licenses/by/4.0/), which permits unrestricted use, distribution, and reproduction in any medium, provided you give appropriate credit to the original author(s) and the source, provide a link to the Creative Commons license, and indicate if changes were made. The Creative Commons Public Domain Dedication waiver (http://creativecommons.org/publicdomain/zero/1.0/) applies to the data made available in this article, unless otherwise stated. 
the estimation of absolute CVD risk to determine whether preventive drugs should be initiated [12-16]. Recently in India, the central government launched the National Program on prevention and control of Cancer, Diabetes, Cardiovascular diseases, and Stroke (NPCDCS). As India does not have locally developed algorithms to predict CVD risk, WHO/ISH risk charts for SEAR-D region (details are explained in the methodology section) are recommended for clinical use [17]. The program advocates the use of BP lowering drugs in patients with intermediate CVD risk and $\mathrm{BP}$ levels $\geq 140 / 90 \mathrm{mmHg}$ and those with high CVD risk and BP levels $\geq 130 / 80 \mathrm{mmHg}$ [17]. NPCDCS was initiated in 2010 and is being rolled out across India in a phased manner. Currently, the program has been implemented in 100 of a total 675 districts, but little is known about its adoption and the potential consequences.

The objectives of the current analyses were to describe the population distribution of $\mathrm{BP}$ and CVD risk in a large rural Indian community, to describe current BP treatment patterns, and to compare the efficiency of single risk factor and absolute CVD risk approaches to $\mathrm{BP}$ lowering in this setting.

\section{Methods}

The data used in these analyses were collected as the baseline assessment of a cluster randomized trial (SMARThealth India) evaluating an intervention aimed at improving CVD risk management [18]. A full household survey was conducted in 54 villages in Andhra Pradesh, India between February 2014 and May 2014.

\section{Participant selection}

A total of 18 Primary Healthcare Centers (PHCs), broadly representative of West Godavari District of Andhra Pradesh were selected for participation in the SMARThealth India trial. Of the four revenue divisions of West Godavari district, all except three PHCs belonging to the Narsapur revenue division were selected based on trial eligibility. A further three PHCs were included from the neighboring Eluru revenue division [18]. Three villages were randomly selected from each PHC and a census list comprising the age and sex of all residents was enumerated from the 54 villages. All eligible persons of age 40 years and above were identified and interviewed after obtaining written informed consent. If an individual was not available at the initial visit, up to three additional visits were made to obtain the required data.

\section{Data collection}

A questionnaire was administered to collect information on socio-demographic variables, CVD risk factors, known chronic conditions and current drug treatments.
Each participant had their BP recorded in the seated position using an automated sphygmomanometer (Model UA-767PBT-C40, A\&D Medical, Tokyo, Japan) after at least $5 \mathrm{~min}$ of rest. The measurement was done thrice, with each measurement made at least 2 min apart. The average of the last two readings was considered for the study. Finger prick capillary blood glucose was estimated using a point-of-care device (Abbott FreeStyle Optium, Alameda, California, USA) with fasting status at the time of sampling recorded.

\section{Estimation of CVD risk}

Ten year risk of fatal or non-fatal major CVD event (myocardial infarction or stroke) was estimated using algorithms based on the World Health Organization/ International Society for Hypertension (WHO/ISH) risk charts [19]. These are color-coded charts tailored to 14 WHO epidemiological sub-regions, including South-East Asian Region-D (SEAR D; includes India). The risk charts predict the risk of CVD based on age, sex, smoking status, level of blood cholesterol, BP, and absence or presence of diabetes. There are two types of charts available - high information charts, for use when blood cholesterol information is available, and low information charts in the absence of cholesterol information. As blood cholesterol was not measured in this study, the low information charts were used. These charts use categories of risk factors: age (40 to $49,50-59,60-69$, 70 years, and older), sex (male, female), smoking (no, smoker, or ex-smoker $<12$ months), systolic BP $(<129.9$, 130 to $149.9,150$ to 169.9 , and $>170 \mathrm{mmHg}$ ), and presence of diabetes (fasting blood glucose $\geq 126 \mathrm{mg} \%$; non-fasting blood glucose $\geq 200 \mathrm{mg} \%$ ) to estimate 10 -year cardiovascular risk. The non-fasting blood glucose threshold used for diagnosis of diabetes is consistent with other population-based diabetes screening programs in India [20].

To estimate the population distribution of CVD risk, pre-treatment BP levels were imputed for all participants reporting use of BP lowering medications. This was done by using the method described by Wald and Law for calculating the pre-treatment systolic and diastolic BP levels, as $80 \%$ of the high-risk patients on BP lowering treatment in the current study were on a single drug regimen [21]. The risk charts allocate individuals into the 5 risks groups: $<10 \%, 10-19 \%, 20-29 \%, 30-39 \%$, and $\geq 40 \%$. Any patient with established coronary heart disease, cerebrovascular disease, peripheral vascular disease or with a BP $>160 / 100 \mathrm{mmHg}$ are categorised as high risk without the need for formal risk assessment. The risk charts predict risk for individuals aged 40 to 79 years; for the current analyses, age was fixed at 79 years for individuals aged 79 or older. 


\section{Estimation of treatment benefit with different strategies for BP lowering}

First, we estimated the number of events that are likely to occur in the study population if it was fully untreated over the next ten years. In these analyses, pre-treatment $\mathrm{BP}$ levels were imputed for individuals taking BP lowering treatment. As the $\mathrm{WHO} / \mathrm{ISH}$ charts assign an individual to a category of risk, rather than an integer, the median value for each risk category was used as an indicator of average risk in each category. For example, for the category of $<10 \%$ risk the mid-point value of $5 \%$ was used, for the category of $10-20 \%$ the mid-point value of $15 \%$ was used, and so forth. For the category of $>40 \%$ (which included those with known CVD or BP $>160$ / 100 ), a mid-point value of $50 \%$ was used. The mid-point value of risk for each category was then applied to the number of individuals within that risk category, and combining these values provided a total number across the population.

The next step was to estimate the number of events that would be averted under different treatment paradigms. Numerous randomized trials have shown that BP lowering reduces the relative risk of CVD events across a broad range of initial BP or CVD risk levels [22-25]. We used a relative risk reduction of $15 \%$ based on recent analyses of the Blood Pressure Lowering Treatment Trialists' Collaboration [25]. For examining risk-based treatment paradigms, we only used three categories of risk: participants with a 10 -year risk of $\geq 30 \%$ were grouped along with those with established CVD and BP > 160/ $100 \mathrm{mmHg}$ as "high risk"; participants with absolute risk of $20-30 \%$ as "intermediate risk", and $<20 \%$ as "low risk". Participants were also classified as having or not having "hypertension" based on BP thresholds of 140/ $90 \mathrm{mmHg}$. The BP lowering treatment paradigms that were compared to an untreated population were: 1) current practice; 2) treating people with "hypertension" using the 140/90 $\mathrm{mmHg}$ threshold; 3) treatment according to the new Indian NPCDCS guidelines (drug therapy recommended in patients with CVD risk $20-30 \%$ and BP levels $\geq 140 / 90 \mathrm{mmHg}$ or CVD risk of $\geq 30 \%$ and BP levels $\geq 130 / 80 \mathrm{mmHg}$ [17]; 4) treating everyone in the intermediate and high risk categories (regardless of BP level); and 5) treating only those in the high risk category (regardless of BP level).

\section{Indicative cost-effectiveness analyses}

The cost-effectiveness of each of the strategies relative to current practice in terms of cost per disability adjusted life years (DALYS) averted were estimated. Costs included costs of CV medication and potential savings associated with reduced hospitalisation from CVD events over 10 years. Medication cost was assumed to be 10 cents per day based on the costs of antihypertensive medications in India [26] (for a total of 10 years in case of high risk) and cost of hospitalization was estimated to be 200 USD for each event [27]. DALYs were determined by dividing total burden in terms of disability adjusted life year lost due to coronary heart diseases with the total number of acute coronary events per year in India based on current burden of disease estimates $[28,29]$. These were then applied to the estimates of CVD events averted with each strategy.

\section{Sensitivity analyses}

Sensitivity analyses were performed with the following differing assumptions to those made for the primary analyses: 1) relative risk reduction of CVD events with BP lowering drug therapy (10\% and $20 \%) ; 2$ ) estimated pre-treatment BP levels for those already on treatment (10 $\mathrm{mmHg}$ lower SBP and $5 \mathrm{mmHg}$ lower DBP; and $5 \mathrm{mmHg}$ lower SBP and $3 \mathrm{mmHg}$ lower DBP); and 3) average 10-year CVD risk for individuals with an estimated risk in the $>40 \%$ band using the $\mathrm{WHO} / \mathrm{ISH}$ charts (40\% and 60\%).

\section{Statistical analysis}

Post-stratification weights were used to adjust for the survey design and sampling methods, both at the PHC and the village level. The PHC weight was based on the ratio of the 24 eligible PHCs in the West Godavari region to the sampled 18 PHCs. Village weight was the ratio of the total number of villages in each PHC to the sampled three villages per PHC. The final weight was calculated as a product of the PHC weight and the village weight. This provided appropriate standardized estimates for the population of 24 PHCs of West Godavari region and minimized any potential sampling bias. The population distribution based on the age and sex of the weighted sample population was similar to the population distribution of the West Godavari district derived from the Government of India census data [30].

Statistical analyses were carried out using statistical package SAS 9.3 (SAS, NC, USA). The "Surveyfreq", "Surveymean", and "Surveyreg" procedures were used to include survey weights, where relevant. Overall and age and sex stratum- specific estimates of risk factor levels were reported. Means and proportions were presented with $95 \%$ confidence intervals. Risk factor levels were compared between groups using independent $t$-tests for continuous variables and chi-square tests for proportions. A $p$-value of $<0.05$ was considered to indicate a result unlikely to have been observed by chance.

\section{Results}

\section{Participant characteristics}

The eligible study population (age $\geq 40$ years) from 54 villages was 74,402 . Data were collected from 62,254 
(83.7\%) participants; $10,332(13.9 \%)$ were not available for interview and 1816 (2.4\%) refused participation. Non-participants were on average younger (43.0 vs. 54.1 years, $p<0.001)$ and more likely to be male $(51.6 \%$ vs. $46.8 \%, \mathrm{p}<0.001)$ than participants. Diabetes status was unknown in 60 individuals, thus data from 62,194 individuals (Table 1) were included in these analyses.

\section{Classification of CVD risk}

Four percent of the study population reported established CVD. After imputing pre-treatment BP levels in patients already on treatment, $11.8 \%$ had "hypertension" using a BP threshold of $160 / 100 \mathrm{mmHg}$ and $29.9 \% \mathrm{had}$ "hypertension" using a BP threshold of 140/90 $\mathrm{mmHg}$. The proportions having low, intermediate and high 10 -year CVD risk were $76 \cdot 8 \%, 5 \cdot 3 \%$, and $17 \cdot 9 \%$, respectively. Fewer individuals than may be expected were classified at intermediate risk; this was largely a result of those with $\mathrm{BP}>160 / 100 \mathrm{mmHg}$ being automatically classified as high risk. There was substantial overlap in systolic BP across CVD risk categories (Fig. 1).

\section{Blood pressure management}

A total of 12,230 individuals (19.6\%) were taking BP lowering medication at the time of data collection. Imputing pre-treatment BP levels, $47.6 \%$ of those currently treated were classified as low risk (Fig. 2). Conversely, $4.2 \%$ and $11.8 \%$ of untreated individuals were estimated to be at intermediate or high risk, respectively.

\section{Comparison of treatment paradigms}

If the population were completely untreated, an estimated 9442 CVD events would occur over ten years. Currently, approximately one in five individuals receive BP lowering treatment.

\section{Comparison of alternate strategies to current practice}

Targeting all intermediate- or high-risk individuals would result in a slightly greater proportion being treated, but

Table 1 - Characteristics of the study population ${ }^{a}$

\begin{tabular}{|c|c|c|c|c|}
\hline & Overall $(n=62,194)$ & Male $(n=29,097)$ & Female $(n=33,097)$ & $p$-values \\
\hline Age (years), mean (95\% Cl) & $54 \cdot 0(53 \cdot 7-54 \cdot 3)$ & $54 \cdot 7(54 \cdot 4-55 \cdot 1)$ & $53 \cdot 3(53 \cdot 0-53 \cdot 6)$ & $<0.001$ \\
\hline Female, \% (95\% Cl) & $53.2(52.5-53.9)$ & & & \\
\hline Currently smoking, \% (95\% Cl) & $21.9(20 \cdot 6-23 \cdot 2)$ & $41.0(38.5-43 \cdot 4)$ & $5 \cdot 1(4 \cdot 4-5 \cdot 8)$ & $<0.001$ \\
\hline Currently chewing tobacco, \% (95\% Cl) & $1 \cdot 5(1 \cdot 2-1 \cdot 8)$ & $3 \cdot 1(2 \cdot 4-3 \cdot 8)$ & $0 \cdot 1(0 \cdot 0-0 \cdot 1)$ & $<0.001$ \\
\hline Established CVD, \% (95\% Cl) & $4.0(3 \cdot 7-4 \cdot 3)$ & $5 \cdot 0(4 \cdot 6-5 \cdot 3)$ & $3 \cdot 2(2 \cdot 8-3 \cdot 6)$ & $<0.001$ \\
\hline Myocardial infarction/angina, \% (95\% Cl) & $2 \cdot 3(2 \cdot 0-2 \cdot 6)$ & $2 \cdot 7(2.4-3.0)$ & $2 \cdot 0(1.7-2 \cdot 3)$ & $<0.001$ \\
\hline Stroke, \% (95\% Cl) & $1.8(1.6-1.9)$ & $2 \cdot 3(2 \cdot 1-2 \cdot 6)$ & $1.2(1.0-1.5)$ & $<0.001$ \\
\hline Peripheral vascular diseases, \% (95\% Cl) & $0.1(0.1-0.2)$ & $0.2(0.1-0.3)$ & $0.1(0.0-0.1)$ & $<0.001$ \\
\hline Self-reported diabetes, \% (95\% Cl) & $11 \cdot 6(10 \cdot 6-12 \cdot 6)$ & $11 \cdot 3(10 \cdot 2-12 \cdot 3)$ & $11 \cdot 8(10 \cdot 8-12 \cdot 9)$ & 0.143 \\
\hline All diabetes, \% (95\% Cl) & $18 \cdot 0(16 \cdot 8-19 \cdot 2)$ & $17.8(16.6-18.9)$ & $18.3(16.9-19.6)$ & 0.250 \\
\hline $\mathrm{SBP}(\mathrm{mmHg})$, mean $(95 \% \mathrm{Cl})$ & $126 \cdot 3(125 \cdot 2-127 \cdot 3)$ & $124 \cdot 2(123 \cdot 4-125 \cdot 1)$ & $128 \cdot 1(126 \cdot 8-129 \cdot 4)$ & $<0.001$ \\
\hline DBP $(m m H g)$, mean $(95 \% \mathrm{Cl})$ & $79 \cdot 8(79 \cdot 2-80 \cdot 4)$ & $79.4(78.8-79.9)$ & $80 \cdot 3(79 \cdot 6-80 \cdot 9)$ & $<0.001$ \\
\hline BP lowering treatment, \% (95\% Cl) & $19.6(18.4-20.9)$ & $16 \cdot 1(15 \cdot 1-17 \cdot 2)$ & $22 \cdot 7(21 \cdot 2-24 \cdot 2)$ & $<0.001$ \\
\hline \multicolumn{5}{|c|}{ 10-year adjusted cardiovascular risk, $\%(95 \% \mathrm{Cl})^{\mathrm{b}}$} \\
\hline$<10 \%$ risk & $63.9(62.5-65 \cdot 2)$ & $63.3(61 \cdot 8-64 \cdot 8)$ & $64 \cdot 4(62 \cdot 6-66 \cdot 1)$ & 0.168 \\
\hline $10-20 \%$ risk & $13.0(12.5-13.5)$ & $13.9(13.0-14.7)$ & $12 \cdot 2(11 \cdot 7-12 \cdot 6)$ & $<0.001$ \\
\hline 20-30\% risk & $5 \cdot 3(4 \cdot 9-5 \cdot 6)$ & $5.9(5 \cdot 4-6 \cdot 4)$ & $4.8(4.5-5.0)$ & $<0.001$ \\
\hline $30-40 \%$ risk & $1 \cdot 2(1 \cdot 1-1 \cdot 3)$ & $1.8(1 \cdot 6-2 \cdot 1)$ & $0.6(0.5-0.7)$ & $<0.001$ \\
\hline$>40 \%$ risk & $0.8(0.8-0.9)$ & $0.6(0.5-0.7)$ & $1.0(0.9-1.2)$ & $<0.001$ \\
\hline Established CVD & $4.0(3.7-4 \cdot 4)$ & $5 \cdot 0(4 \cdot 6-5 \cdot 3)$ & $3 \cdot 2(2 \cdot 8-3 \cdot 6)$ & $<0.001$ \\
\hline $\mathrm{BP} \geq 160 / 100 \mathrm{mmHg}$ & $11 \cdot 8(11 \cdot 1-12 \cdot 5)$ & $9.5(8.9-10 \cdot 1)$ & $13 \cdot 8(12 \cdot 9-14 \cdot 8)$ & $<0.001$ \\
\hline \multicolumn{5}{|c|}{ 10-year adjusted cardiovascular risk groups, $\%(95 \% \mathrm{Cl})^{\mathrm{b}}$} \\
\hline Low risk $(I+\mid I)$ & $76.8(75.7-78.0)$ & $77 \cdot 2(76 \cdot 1-78 \cdot 4)$ & $76.5(75 \cdot 1-78 \cdot 0)$ & 0.251 \\
\hline Intermediate risk (III) & $5.3(4.9-5.6)$ & $5.9(5.4-6.4)$ & $4.8(4.5-5 \cdot 1)$ & $<0.001$ \\
\hline High risk $(I V+V+V I+V I I)$ & $17.9(16.9-18.8)$ & $16.9(16 \cdot 1-17.7)$ & $18.7(17 \cdot 4-20 \cdot 0)$ & 0.001 \\
\hline
\end{tabular}

Weighted estimates ${ }^{\mathrm{b}} \mathrm{After}$ estimation of pre-treatment BP for those on BP lowering treatment 


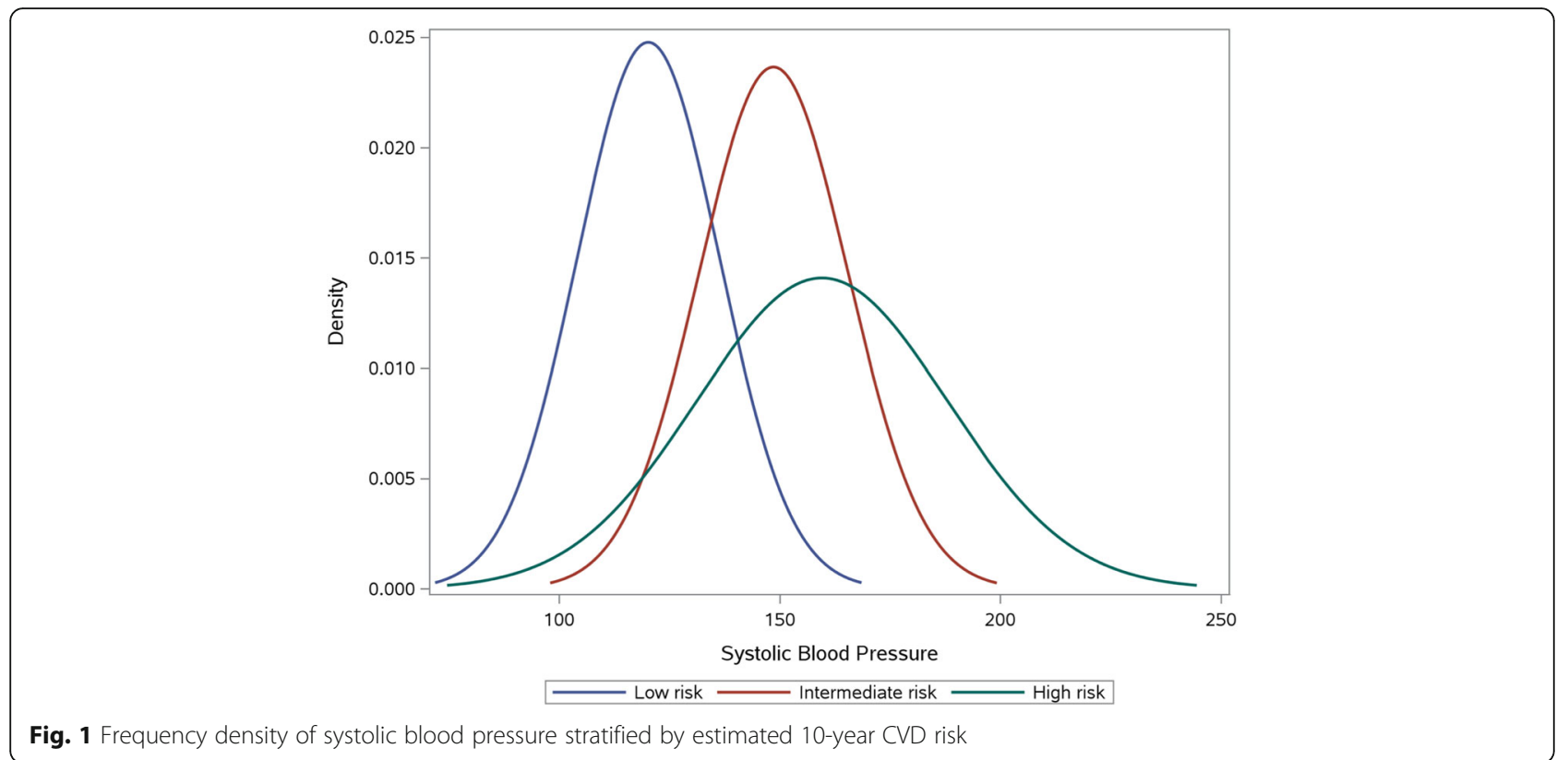

would almost double the number of events averted over ten years ( $5 \cdot 3 \%$ vs. $9.9 \%$; Table 2$)$. If only high-risk individuals were targeted for treatment, there would be a $9 \%$ reduction in total population treated, but would lead to $62.7 \%$ greater number of averted events. Implementation of NPCDCS guidelines would result in the treatment of a similar number of individuals, but with a $77.3 \%$ increase in the number of events averted.

\section{Comparison of alternate strategies to 'hypertension' strategy}

Treatment of all intermediate- and high-risk individuals would result in $29.1 \%$ reduction in proportion of population treated with $7.4 \%$ greater number of averted events. Treatment as per the NPCDCS guidelines would lead to a similar number of events averted but would require $35.5 \%$ lesser number of individuals treated. If only high risk individuals were treated, there would be a $45.2 \%$

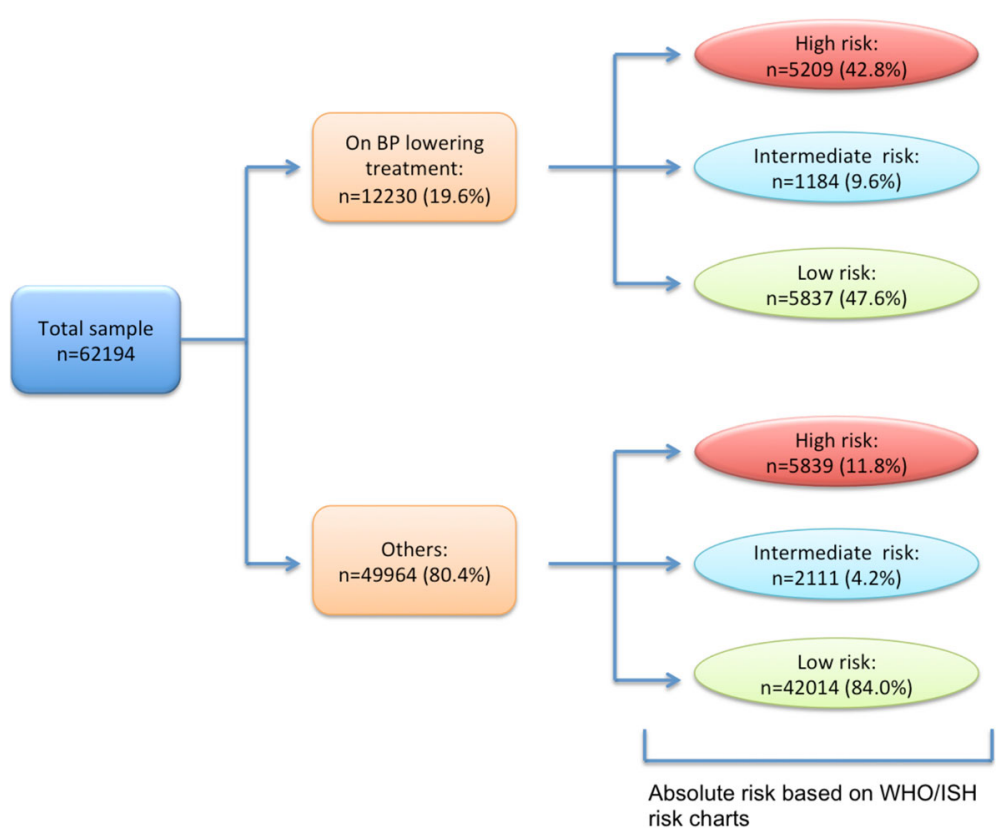

Fig. 2 Estimated 10-year CVD risk distribution 


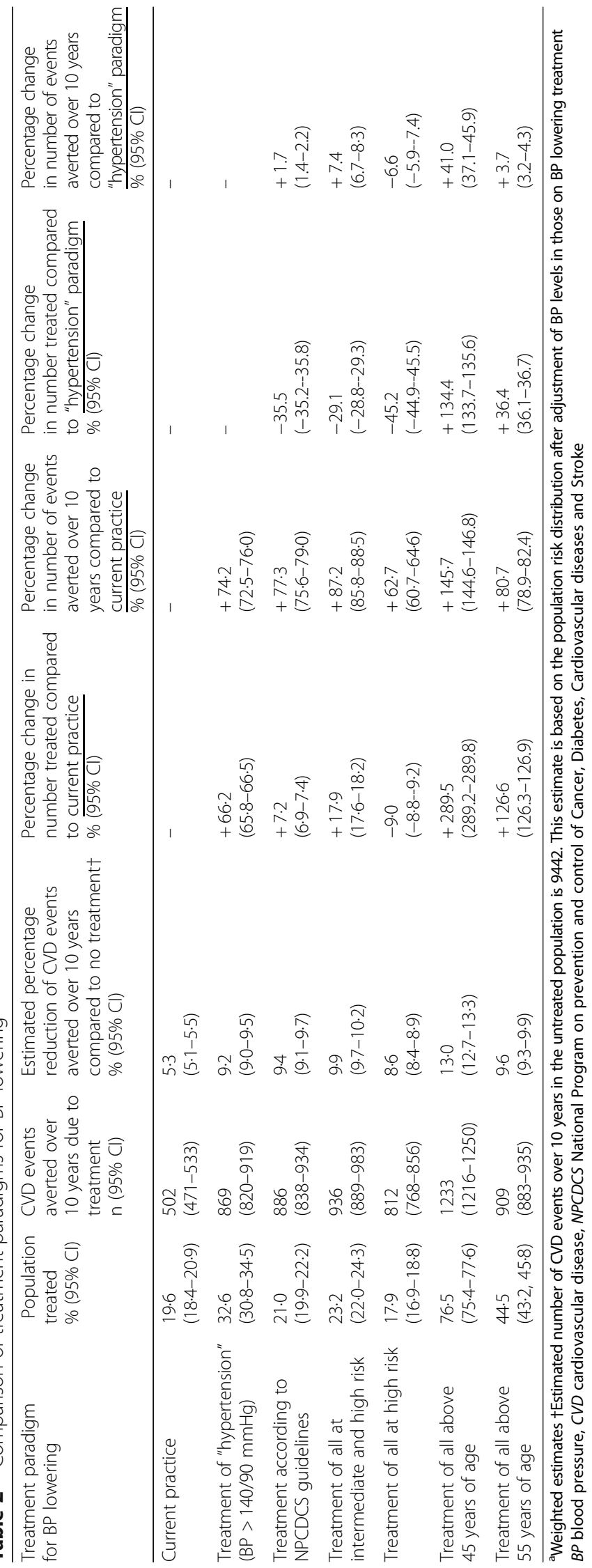


reduction in total population treated and $6.6 \%$ reduction in the number of events averted.

The cost effectiveness estimates found that treatment of all at high risk relative to current practice was cost saving (dominant). Treatment as per the NPCDCS guidelines (ICER $=27 / \mathrm{DALY}$ averted) and treatment of all at intermediate and high risk (ICER $=73.2 /$ DALY averted) were each found to be highly cost effective (Table 3). These conclusions were based on the World Health Organization benchmarks (highly cost effective: ICER < one time per capital gross national income (\$1570); cost-effective: ICER < three times per capital gross national income $(\$ 4710))[31,32]$.

\section{Sensitivity analyses}

Varying the major assumptions used in these analyses resulted in minimal to modest changes to estimates of the treated population size and numbers of events averted, however the differences between treatment paradigms remained broadly similar (Tables $1-6$, online Appendix).

\section{Discussion}

There are three important findings from this large cross-sectional study. First, a substantial proportion of this rural Indian population is at elevated risk of CVD. Second, many low-risk individuals currently receive BP lowering therapy, while treatment gaps among intermediate- and high-risk populations remain. Third, the widespread implementation of Indian guidelines that encourage an absolute risk approach to BP lowering treatment is highly cost-effective and in the specific case of treating all at high risk, cost-saving. Through this approach many more CVD events could be averted by treating fewer individuals, as well as significant amounts of money saved, if current practice was replaced with a strategy that only treats individuals at high CVD risk, regardless of BP level.

The finding of substantial CVD risk-factor burden in a rural Indian population is no longer surprising and reflects a rapid epidemiological transition that is affecting disadvantaged groups in low- and middle-income countries globally [7, 19]. The threat that CVD and other non-communicable diseases pose is now widely recognized with the World Health Assembly's adoption of Global Action Plan for Prevention and Control of Non-communicable Diseases 2013-2020 [33]. This includes a global " 25 by 25 " goal - achieving $25 \%$ relative reduction in overall mortality from CVD, cancer, diabetes, and chronic respiratory diseases by 2025 . Four of the nine targets within the Global Action Plan directly relate to control and management of BP related disease - namely; reducing population intake of salt/sodium; reducing or containing $\mathrm{BP}$; essential drug availability; and appropriate drug therapy to prevent heart attack and stroke. Cost-effective strategies to identify and provide appropriate BP lowering drug treatment to individuals are therefore crucial to achieving at least some of these targets.

The advantages of basing treatment decisions on an individual's CVD risk, rather than using an often-arbitrarily defined threshold level of an individual risk-factor have been long recognized [13, 19, 25, 34]. A recent large meta-analysis of BP lowering trials further strengthens the rationale for taking a risk-based approach, demonstrating similar CVD event protection regardless of initial BP level [25]. Therefore, as expected, the greatest absolute benefits of treatment accrued to those individuals at highest baseline risk. Strategies for identifying and treating individuals at high CVD risk are particularly important in low- and middle-income countries with major resource constraints and large under-treated populations [35]. Despite guidelines globally having an increased focus on absolute CVD risk-based approaches to blood pressure control [25], most practice appears to be entrenched on traditional paradigms that solely treat "hypertension".

Our data indicate that current treatment in rural Andhra Pradesh is primarily driven by BP level rather than risk level, with approximately one-half of those on treatment being low risk, and only about $45 \%$ of individuals at high risk taking BP lowering drugs. The NPCDCS program in India, introduced in 2010, has largely taken a risk-based approach; further implementation of these recommendations would avert more events with the same proportion of the population currently being treated. Approximately 1.7 million events in individuals 40 years and above in Andhra Pradesh would be averted when compared to 0.9 million events, if the NPCDCS program recommendations are followed. Our data indicate that other risk-based approaches may be even more cost-efficient, an important consideration if available drug resources are severely constrained. We show that a similar number of CVD events could be averted as with current treatment, but with only half of the number of individuals requiring treatment using a 10-year absolute CVD risk threshold of $30 \%$, this means 14 patients would require drug treatment for ten years to avert a CV event compared to 26 with current practice. Similar conclusions have been reached in studies in high-income countries [36, 37], but to the best of our knowledge this is the first-time comprehensive population-based data in a low- and middle-income country have established the advantages of an absolute risk approach to BP management.

The strengths of this study include collection of data on risk factors for CVD in virtually all eligible individuals in 54 villages of a south Indian state, likely to be generalizable to much of rural India. Robust, reproducible 


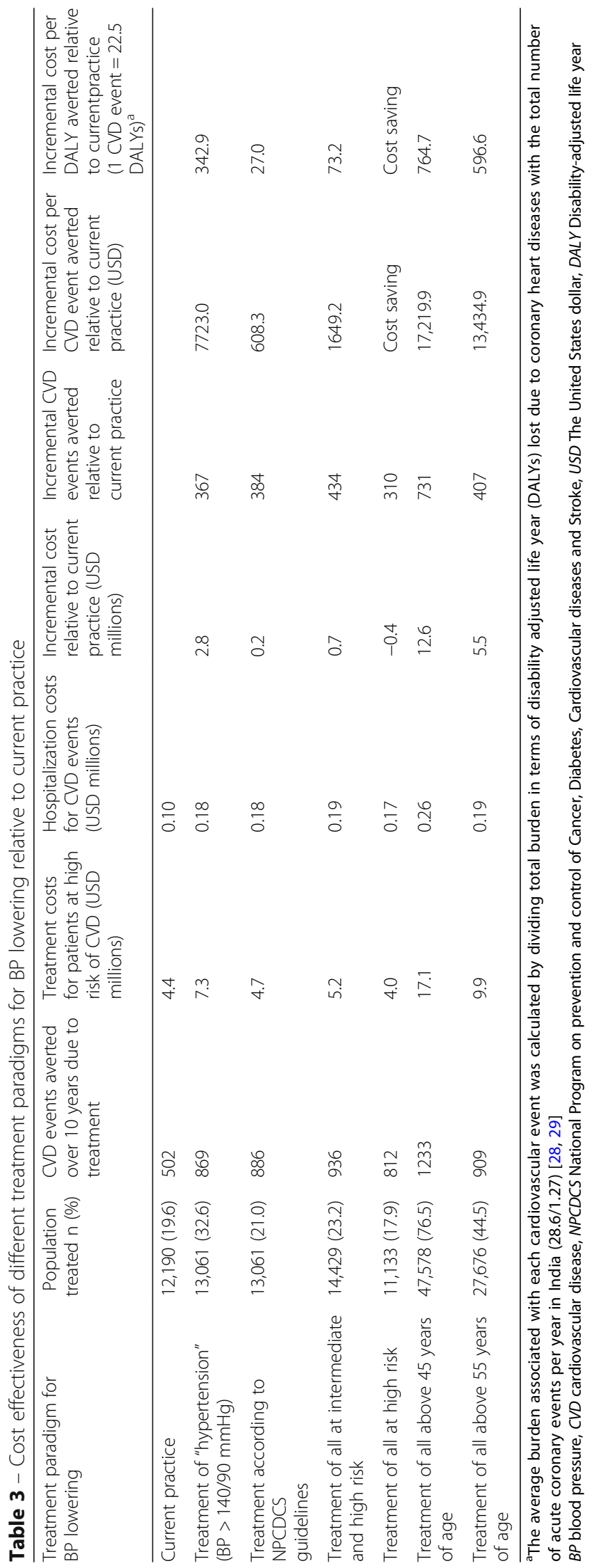


methods of data collection were used to collect these data. However, there are also some limitations. While only $13 \%$ of those eligible did not participate, these individuals were on average younger and more likely to be male than study participants. The former might have resulted in an over-estimation of population levels of CVD risk, however the opposite is true of the latter. The effectiveness of an absolute-risk approach relies on accurate CVD risk-assessment tools. While it has been adopted by NPCDCS, the performance of the WHO-ISH charts has not been adequately evaluated in the Indian context, and no other validated tools currently exist. The use of random (rather than fasting) blood glucose measurements (also adopted by the regular screening processes in NPCDCS) may have resulted in under-diagnosis of diabetes and thus under-estimation of the size of the high-risk population.

\section{Study limitations}

We have made several assumptions in describing the effects of different treatment paradigms, based on meta-analyses of relevant clinical trials [38]. However sensitivity analyses indicate our conclusions remain robust to varying assumptions (please see Additional file 1). It should also be noted that treatment of other CVD risk factors was not considered in these analyses. In relation to use of other medications, recent studies in similar communities have demonstrated that even in the context of secondary prevention, the use of statins (6\% in coronary heart disease and $1 \%$ in stroke), and antiplatelet therapy (19.4\% in coronary heart disease and $11.8 \%$ in stroke) is very low, improved coverage with these medicines could further reduce events [39]. In the absence of other locally developed algorithms, the WHO/ISH risk charts for SEAR-D region were used to define the CVD risk in this study. These risk charts are in the process of being replaced because of concerns about their calibration in the target population. Newer risk charts will not likely influence the reported ranking of the effectiveness of different interventions, but could influence the predicted absolute numbers of events prevented and the cost-effectiveness estimates. In generating cost effectiveness estimates we applied data on India-specific average costs of pills and DALYs from the published literature to provide an indication of the investment case for each of the strategies. Although the estimates are crude, any error was unlikely to have affected the reported ranking of different interventions and findings that indicated overwhelmingly the economic arguments for shifts in treatment paradigm away from current practice. Finally, the study did not recruit individuals above 85 years, which is likely to have excluded few individuals, but a greater proportion at higher risk.

\section{Conclusion}

An absolute risk based approach is important for preventing BP related diseases, particularly in low- and middle-income countries where resource constraints are a major barrier to CVD prevention. Guidelines are changing, but it will take concerted effort to change the decades-old paradigm of single-risk factor screening and management. In this study, we present an emphatic case for doing so based on population health outcomes and economic criteria. For the risk-based approach to be maximally effective, development and use of tools that easily and accurately predict an individual's absolute risk of CVD is an urgent priority. Even if such tools were available, it is likely that healthcare providers will be slow to adopt new paradigms of treatment in the presence of numerous health system barriers, but unless funders and policy makers very rapidly re-orient "hypertension" programmes to CVD risk management, the likelihood of achieving some of the $25 \times 25$ targets will be significantly compromised.

\section{Additional file}

Additional file 1: Tables S1-S6. We have made several assumptions in describing the effects of different treatment paradigms, based on metaanalyses of relevant clinical trials. The additional file 1 consists results of sensitivity analyses conducted to indicate our conclusions remain robust to varying assumptions. (DOCX $34 \mathrm{~kb}$ )

\section{Abbreviations}

BP: Blood Pressure; CVD: Cardiovascular disease risk; DALYS: disability adjusted life years; NPCDCS: National Program on prevention and control of Cancer, Diabetes, Cardiovascular diseases, and Stroke; PHCs: Primary Healthcare Centers; SEAR D: South-East Asian Region-D; WHO/ISH: World Health

Organization/ International Society for Hypertension

\section{Acknowledgement}

Not applicable

\section{Funding}

This study was funded by an Australian National Health and Medical Research Council (NHMRC) Global Alliances for Chronic Disease Grant (ID1040147). The funder had no role in study design, data collection and analysis, decision to publish, or preparation of the manuscript. DPRA is supported by the Australian Agency for International Development (AusAID), DPE is supported by a NHMRC post-doctoral fellowship, and AP and SJ are supported by NHMRC Senior Research Fellowships. RJ is supported by a National Health Foundation Future Leader Fellowship. AR is supported by the Wellcome Trust. PM is an Intermediate Career Fellow of The Wellcome Trust/DBT India Alliance.

\section{Availability of data and materials}

The datasets used and analysed during the current study is a part of a larger randomised controlled trial (results yet to be published) and are available from the corresponding author on reasonable request.

\section{Authors' contributions}

DPra analysed and interpreted the data. KM and AR1 supported in the collection and preparation of the data. GDC guided the risk calculation and provided key inputs to the data collection process. SC and SH validated the data analyses. DP and SJ provided key inputs to the interpretation of the data. DPra with AP prepared the initial draft of the paper. SM, AR2, DPrab, PM, EA and $\mathrm{RJ}$ provided key inputs to the discussion in this paper. All authors read and 
approved the final manuscript and agreement to be accountable for all aspects of the work.

\section{Ethics approval and consent to participate}

The study protocol conforms to the ethical guidelines of the 1975 Declaration of Helsinki as reflected in a priori approval by The Centre for Chronic Disease Control Ethics Committee, New Delhi and the University of Sydney Human Research Ethics Committee, Sydney. All the participants were interviewed after obtaining written informed consent to participate in this study.

\section{Consent for publication}

This is not applicable as individual person's details, images or videos are not being presented.

\section{Competing interests}

The authors declare that they have no competing interests.

\section{Publisher's Note}

Springer Nature remains neutral with regard to jurisdictional claims in published maps and institutional affiliations.

\section{Author details}

${ }^{1}$ The George Institute for Global Health, Hyderabad, India. ${ }^{2}$ University of New South Wales, Sydney, Australia. ${ }^{3}$ The George Institute for Global Health, University of New South Wales, Sydney, Australia. ${ }^{4}$ The George Institute for Global Health, The University of New South Wales, Sydney, Australia. ${ }^{5}$ The George Institute for Global Health, Hyderabad, India. ${ }^{6}$ Institute of Biomedical Engineering, University of Oxford, Oxford, UK. ${ }^{7}$ Centre for Chronic Disease Control, New Delhi, India. ${ }^{8}$ London School of Hygiene and Tropical Medicine, London, UK. 'Department of Biomedical Informatics, Emory University, Atlanta, GA, USA. ${ }^{10}$ Department of Biomedical Engineering, Georgia Institute of Technology, Atlanta, GA, USA. ${ }^{11}$ The George Institute for Global Health, Delhi, India. ${ }^{12}$ Monash University, Melbourne, Australia.

\section{Received: 19 February 2018 Accepted: 23 October 2018} Published online: 15 November 2018

\section{References}

1. Lozano R, Naghavi M, Foreman K, et al. Global and regional mortality from 235 causes of death for 20 age groups in 1990 and 2010: a systematic analysis for the global burden of disease study 2010. Lancet. 2012;380:2095-128.

2. Murray CJL, Lopez AD. The global burden of disease: a comprehensive assessment of mortality and disability from diseases, injuries and risk factors in 1990 and projected to 2020. Cambridge: Harvard University Press on behalf of the World Health Organization and the World Bank; 1996.

3. World Health Organisation. Global status report on noncommunicable diseases 2010. Geneva: World Health Organization; 2011.

4. Kuulasmaa K, Tunstall-Pedoe H, Dobson A, et al. Estimation of contribution of changes in classic risk factors to trends in coronary-event rates across the WHO MONICA project populations. Lancet. 2000;355:675-87.

5. Unal B, Critchley JA, Capewell S. Explaining the decline in coronary heart disease mortality in England and Wales between 1981 and 2000. Circulation. 2004;109:1101-7.

6. Srinath Reddy K, Shah B, Varghese C, Ramadoss A. Responding to the threat of chronic diseases in India. Lancet. 2005;366:1744-9.

7. Gupta R, Joshi P, Mohan V, Reddy KS, Yusuf S. Epidemiology and causation of coronary heart disease and stroke in India. Heart. 2008;94:16-26.

8. Martiniuk AL, Lee CM, Lawes CM, et al. Hypertension: its prevalence and population-attributable fraction for mortality from cardiovascular disease in the Asia-Pacific region. J Hypertens. 2007;25:73-9.

9. Ezzati M, Lopez AD, Rodgers A, Vander Hoorn S, Murray CJ. Selected major risk factors and global and regional burden of disease. Lancet. 2002;360: 1347-60.

10. Summary of the 2007 European Society of Hypertension (ESH) and European Society of Cardiology (ESC) guidelines for the management of arterial hypertension. Vasc Health Risk Manag. 2007;3:783-95.

11. World Health Organisation. Prevention of cardiovascular disease: guidelines for assessment and management of total cardiovascular risk. Geneva: World Health Organization; 2007. http://www.who.int/cardiovascular_diseases/ guidelines/Full\%20text.pdf. Accessed 5 Nov 2018.
12. Williams B, Poulter NR, Brown MJ, et al. British hypertension society guidelines for hypertension management 2004 (BHS-IV): summary. BMJ. 2004;328:634-40.

13. Jackson R. Updated New Zealand cardiovascular disease risk-benefit prediction guide. BMJ. 2000;320:709-10.

14. Marrugat J, D'Agostino R, Sullivan L, et al. An adaptation of the Framingham coronary heart disease risk function to European Mediterranean areas. J Epidemiol Community Health. 2003;57:634-8.

15. Stone NJ, Robinson J, Lichtenstein AH, et al. 2013 ACC/AHA guideline on the treatment of blood cholesterol to reduce atherosclerotic cardiovascular risk in adults. A Report of the American College of Cardiology/American Heart Association Task Force on Practice Guidelines 2013.

16. Perk J, De Backer G, Gohlke H, et al. European guidelines on cardiovascular disease prevention in clinical practice (version 2012). The fifth joint task force of the European Society of Cardiology and Other Societies on cardiovascular disease prevention in clinical practice (constituted by representatives of nine societies and by invited experts). Eur Heart J. 2012; 33:1635-701.

17. Government of India-WHO. National Programme for Prevention and Control of Diabetes, Cardiovascular Disease and Stroke - A manual for medical officer. 2008. URL: http://www.searo.who.int/india/topics/cardiovascular_ diseases/NCD_Resources_COMBINED_MANUAL_for_medical_officer.pdf. Accessed 5 Nov 2018.

18. Praveen D, Patel A, McMahon S, et al. A multifaceted strategy using mobile technology to assist rural primary healthcare doctors and frontline health workers in cardiovascular disease risk management: protocol for the SMARTHealth India cluster randomised controlled trial. Implementation science. 2013;8:137.

19. Mendis S, Lindholm LH, Anderson SG, et al. Total cardiovascular risk approach to improve efficiency of cardiovascular prevention in resource constrain settings. J Clin Epidemiol. 2011;64:1451-62.

20. Directorate General of Health Services. Ministry of Health and Family Welfare. Govt. of India. National Programme for Prevention and Control of Cancer, Diabetes, Cardiovascular Diseases and Stroke: Operational Guidelines, 2010. URL: http:// health.bih.nic.in/Docs/Guidelines-NPCDCS.pdf [Accessed: 18 March 2014].

21. Law MR, Morris JK, Wald NJ. Use of blood pressure lowering drugs in the prevention of cardiovascular disease: meta-analysis of 147 randomised trials in the context of expectations from prospective epidemiological studies. BMJ. 2009:338:b1665.

22. Gradman AH, Parise $H$, Lefebvre $P$, Falvey $H$, Lafeuille $M H$, Duh MS. Initial combination therapy reduces the risk of cardiovascular events in hypertensive patients: a matched cohort study. Hypertension. 2013;61: 309-18.

23. Thomopoulos C, Parati G, Zanchetti A. Effects of blood pressure lowering on outcome incidence in hypertension: 3 . Effects in patients at different levels of cardiovascular risk - overview and meta-analyses of randomized trials. J Hypertens. 2014;32(12):2305-14.

24. Thomopoulos C, Parati G, Zanchetti A. Effects of blood pressure lowering on outcome incidence in hypertension: 2 . Effects at different baseline and achieved blood pressure levels - overview and meta-analyses of randomized trials. J Hypertens. 2014;32(12):2296-304.

25. Sundstrom J, Arima H, Woodward M, et al. Blood pressure-lowering treatment based on cardiovascular risk: a meta-analysis of individual patient data. Lancet. 2014;384:591-8.

26. Rachana PR, Anuradha HV, Shivamurthy MC. Anti Hypertensive Prescribing Patterns and Cost Analysis for Primary Hypertension: A Retrospective Study. J Clin Diagn Res. 2014;8(9):HC19-22.

27. Srivastava A, Mohanty SK. Age and sex pattern of cardiovascular mortality, hospitalisation and associated cost in India. PLoS One. 2013;8:e62134.

28. Gupta R. Coronary Heart Disease in India: Absolute Numbers and Economic Burden. BMJ. 2004. Rapid Response.

29. Institute for Health Metrics and Evaluation (IHME). GBD Compare. Seattle: IHME, University of Washington, 2015. URL: http://vizhub.healthdata.org/ gbd-compare. Accessed 5 Nov 2018.

30. Office of the Registrar General. Government of India. Census of India, 2011. URL: http://www.censusindia.gov.in/2011 census/C-series/C-13.html. Accessed 5 Nov 2018.

31. The World Bank. World Development Indicators. GNI per capita, Atlas method. URL: http://data.worldbank.org/indicator/NY.GNP.PCAP.CD. Accessed 5 Nov 2018. 
32. Marseille E, Larson B, Kazi DS, Kahn JG, Rosen S. Thresholds for the costeffectiveness of interventions: alternative approaches. Bull World Health Organ. 2015;93:118-24.

33. World Health Assembly. Follow-up to the Political Declaration of the HighLevel Meeting of the General Assembly on the Prevention and Control of Non-communicable diseases, 2013. URL: http://apps.who.int/gb/ebwha/pdf_ files/WHA66/A66_R10-en.pdf. Accessed 5 Nov 2018.

34. World Health Organisation. World Health Report: reducing risks, promoting healthy life. Geneva; 2002. http://www.who.int/whr/2002/en/whr02_en.pdf. Accessed 5 Nov 2018,

35. Yusuf S, Rangarajan S, Teo K, et al. Cardiovascular risk and events in 17 lowmiddle-, and high-income countries. N Engl J Med. 2014;371:818-27.

36. Baker $S$, Priest $P$, Jackson R. Using thresholds based on risk of cardiovascular disease to target treatment for hypertension: modelling events averted and number treated. BMJ. 2000;320:680-5.

37. Joint British recommendations on prevention of coronary heart disease in clinical practice: summary. British Cardiac Society, British Hyperlipidaemia Association, British Hypertension Society, British Diabetic Association. Bmj. 2000;320:705-8.

38. Rodgers A, Lawes CMM, Gaziano T, Vos T. The Growing Burden of Risk from High Blood Pressure, Cholesterol, and Bodyweight. In: Jamison TD, Breman JG, Measham AR, Alleyne G, Claeson M, Evans DB, Jha P, Mills A, Musgrove $P$, editors. Disease Control Priorities in Developing Countries Washington (DC): World Bank, The International Bank for Reconstruction and Development/The World Bank Group; 2006.

39. Joshi R, Chow CK, Raju PK, et al. Fatal and nonfatal cardiovascular disease and the use of therapies for secondary prevention in a rural region of India. Circulation. 2009:119:1950-5.

Ready to submit your research? Choose BMC and benefit from:

- fast, convenient online submission

- thorough peer review by experienced researchers in your field

- rapid publication on acceptance

- support for research data, including large and complex data types

- gold Open Access which fosters wider collaboration and increased citations

- maximum visibility for your research: over $100 \mathrm{M}$ website views per year

At $\mathrm{BMC}$, research is always in progress.

Learn more biomedcentral.com/submissions 